\title{
Pregnancy in a Woman with Homozygous Familial Hypercholesterolemia Not on Low-Density Lipoprotein Apheresis
}

\author{
Akl C. Fahed, M.D. ${ }^{1}$ Anwar H. Nassar, M.D. ${ }^{2}$ \\ ${ }^{1}$ Department of Genetics, Harvard Medical School, Boston, \\ Massachusetts \\ 2 Department of Obstetrics and Gynecology, American University of \\ Beirut Medical Center, Beirut, Lebanon
}

\begin{abstract}
Address for correspondence and reprint requests Anwar $\mathrm{H}$. Nassar, M.D., Department of Obstetrics and Gynecology, American University of Beirut, P.O. Box 113-6044/B36, Beirut, Lebanon (e-mail: an21@aub.edu.lb).
\end{abstract}

\begin{abstract}
Keywords

- homozygous familial hypercholesterolemia

- pregnancy

- LDL apheresis

- outcome

Pregnancy in women with homozygous familial hypercholesterolemia (FH) has been rarely reported and might pose risks on the mother and her fetus. Although most reported cases remained on low-density lipoprotein (LDL) apheresis, there are no clear guidelines regarding the management of this entity. We report the first case of an uncomplicated pregnancy in a 24-year-old homozygous FH woman who was not maintained on LDL apheresis. FH expresses a wide variability in the phenotype, and management of homozygous $\mathrm{FH}$ cases who desire to become pregnant should be individualized based on preconceptional assessment with frequent antenatal follow-up. Decisions on management should be made after weighing the risks versus benefits of LDL apheresis.
\end{abstract}

\section{Case Report}

A 24-year-old G2, P1, A0, L1 was clinically diagnosed with homozygous familial hypercholesterolemia (FH) at the age of 7 based on strong family history (six affected siblings), lowdensity lipoprotein (LDL) levels above $500 \mathrm{mg} / \mathrm{dL}$, and presence of xanthomas and xanthelasmas. Genetic screening of the family for mutations in LDLR and its promoter, ApoB100, and PCSK9 as part of an earlier study revealed no mutations. ${ }^{1}$ Treatment with statins (atorvastatin calcium $20 \mathrm{mg}$ once daily) and lifestyle modifications (low-fat diet and daily exercise) was instated at the age of 19 , following which the xanthomas resolved. The patient had an uneventful smooth course, full-term pregnancy during that period where she gave birth to a healthy male by cesarean delivery for failure of dilation. During this pregnancy, the patient discontinued statin treatment. The child shows a normal development and has been disease-free during the first 5 years of life. In 2007, the patient was started on LDL apheresis at a rate of two sessions per month. On LDL apheresis, her total cholesterol level was $591 \mathrm{mg} / \mathrm{dL}$, LDL $527 \mathrm{mg} / \mathrm{dL}$, high-density lipoprotein (HDL) $37 \mathrm{mg} / \mathrm{dL}$, and triglycerides $131 \mathrm{mg} / \mathrm{dL}$.

For nonmedical reasons, the patient stopped LDL apheresis in 2009 and was off any kind of therapy as of 3 months preconceptionally. At 25 weeks of gestation of that second pregnancy, she had gained $3.5 \mathrm{~kg}$ to a pregestational body mass index of $23 \mathrm{~kg} / \mathrm{m}^{2}$. She also had higher HDL and triglycerides and lower LDL at 25 weeks (total cholesterol $722 \mathrm{mg} / \mathrm{dL}$, HDL $131 \mathrm{mg} / \mathrm{dL}$, LDL $477 \mathrm{mg} / \mathrm{dL}$, and triglycerides $375 \mathrm{mg} / \mathrm{dL}$ ) compared with the preconceptional period and while on LDL apheresis. Cardiovascular assessment was performed at 25 weeks. Echocardiogram showed mild aortic valve disease (stenosis and regurgitation). Vascular studies showed a plaque in the origin of the internal carotid arteries causing less than $50 \%$ stenosis bilaterally by carotid duplex scan. The intima media thickness was $0.7 \mathrm{~mm}$ on the right and $1.2 \mathrm{~mm}$ on the left side. The ankle-brachial index (ABI) was 0.97 on the right and 0.93 on the left side. $\mathrm{ABI}$ is a noninvasive test of peripheral arterial disease (PAD) in the lower extremities, performed by measuring blood pressure at the arms and received

September 26, 2011

accepted after revision

December 3, 2011

published online

February 22, 2012
Copyright (c 2012 by Thieme Medical Publishers, Inc., 333 Seventh Avenue, New York, NY 10001, USA. Tel: +1(212) 584-4662.
DOI http://dx.doi.org/ 10.1055/s-0032-1305798. ISSN 2157-6998. 
at the ankles. A normal ABI ranges between 0.9 and 1.3, with decreased $A B I$ indicating PAD. Obstetric ultrasound showed measurements commensurate with gestational age with no gross fetal abnormalities and an estimated fetal weight of 819 g. Fetal echocardiogram showed mild tricuspid regurgitation. The course of pregnancy was uneventful with normal blood pressure documented throughout her antenatal care. The patient had a repeat cesarean delivery at 38 weeks of gestation and delivered a healthy male infant weighing $3200 \mathrm{~g}$. The child shows a normal development and is disease free in the first year of life.

\section{Discussion}

Homozygous FH is a very rare disease that might pose risks on the mother and her fetus during pregnancy. Animal and human studies have shown that high maternal cholesterol increases the risk of fetal and maternal complications during pregnancy such as growth restriction, preeclampsia, and abortion. ${ }^{2,3}$ There are no clear guidelines for the management of these rare cases. Several cases of uncomplicated pregnancies of homozygous FH patients on LDL apheresis are reported in the literature and accordingly authors recommended its use. $^{4-7}$ Only few cases reported complications of LDL apheresis in pregnant $\mathrm{FH}$ patients. ${ }^{8}$ We report the first case of an uneventful pregnancy course in a patient who was not on LDL apheresis. Our patient had two uncomplicated pregnancies off LDL apheresis resulting in two healthy boys. This does not necessarily suggest that FH patients should not be treated by apheresis. Nevertheless, such a case should prompt clinicians to weigh the risks versus benefits of LDL apheresis in pregnant women. This is particularly important in FH, a disease that has a great phenotypic variability and whose genotype-phenotype correlations are still poorly understood. ${ }^{9}$ Although this woman was clinically diagnosed with homozygous FH, genetic screening failed to show a mutation, and her LDL levels are slightly lower than what would be expected from the classically described homozygous FH patient in the literature (between 500 and $1000 \mathrm{mg} / \mathrm{dL}$ ).

Patients with homozygous FH have premature atherosclerosis, which very often is present during childbearing age. This might affect the uteroplacental circulation leading to insufficiency, which could contribute to the associated pregnancy complications. The hemodynamic stress during pregnancy may exacerbate preexisting cardiovascular lesions and precipitate acute events, to an extent that some reported homozygous $\mathrm{FH}$ as a contraindication for pregnancy. ${ }^{10}$ Therefore, detailed preconceptional cardiovascular assessment should be performed on women who desire to become pregnant, and this should guide their management. In our case, the patient had only mild aortic and carotid disease, which does not usually result in vascular insufficiency.

Lipid changes during pregnancy have been studied in both normal patients and patients with FH. Physiological lipoprotein changes in a normal pregnancy are due to the effects of estrogen and progesterone on lipoprotein metabolism and are characterized by an increased LDL and triglycerides throughout and a decreased HDL in the third trimester. ${ }^{7}$ Homozygous FH women who desire to become pregnant are at risk of increased exposure to LDL cholesterol due to this unfavorable lipoprotein profile and the need to stop statin therapy, both superimposed on their hypercholesterolemic baseline. In our patient, triglycerides and HDL increased and her LDL decreased despite stopping statins and LDL apheresis. Normalization of LDL during pregnancy has been reported before in a heterozygous $\mathrm{FH}$ patient, ${ }^{11}$ and studies on an animal model of FH showed similar results suggesting an increase in LDL receptor activity during pregnancy. ${ }^{12}$ The mutation status of the patient might play a role in the response of lipid metabolism to the hormonal changes of pregnancy. More studies will need to be done to further elucidate the details of the pathways involved. Until then, physicians should individualize the care of women with homozygous FH who desire to get pregnant and weigh the risks versus benefits of LDL apheresis. A detailed preconceptional assessment and frequent follow-up of lipid profile, cardiovascular status, and the fetus should help guide management decisions.

\section{Acknowledgments}

The authors would like to thank staff and physicians of the Children's Heart Center and Noninvasive Vascular Laboratory at AUBMC, the National LDL-Apheresis Center, and the Nemer Laboratory at the Department of Biochemistry and Molecular Genetics at AUB. This work was supported by the Lebanese National Council for Scientific Research (CNRS Grant No. 114110-522177).

\section{References}

1 Fahed AC, Safa RM, Haddad FF, et al. Homozygous familial hypercholesterolemia in Lebanon: a genotype/phenotype correlation. Mol Genet Metab 2011;102:181-188

2 De Assis SM, Seguro AC, Helou CM. Effects of maternal hypercholesterolemia on pregnancy and development of offspring. Pediatr Nephrol 2003;18:328-334

3 Thadhani R, Stampfer MJ, Hunter DJ, Manson JE, Solomon CG, Curhan GC. High body mass index and hypercholesterolemia: risk of hypertensive disorders of pregnancy. Obstet Gynecol 1999;94: 543-550

4 Anedda S, Mura S, Marcello C, Pintus P. HELP LDL-apheresis in two cases of familial hypercholesterolemic pregnant women. Transfus Apheresis Sci 2011;44:21-24

5 Ertorer ME, Guvenc B, Haydardedeoglu B, Tekinturhan F. A case report of the cascade filtration system: a safe and effective method for low-density lipoprotein apheresis during pregnancy. Ther Apher Dial 2008;12:396-400

6 Cashin-Hemphill L, Noone M, Abbott JF, Waksmonski CA, Lees RS. Low-density lipoprotein apheresis therapy during pregnancy. Am J Cardiol 2000;86:1160, A10

7 Klingel R, Göhlen B, Schwarting A, Himmelsbach F, Straube R. Differential indication of lipoprotein apheresis during pregnancy. Ther Apher Dial 2003;7:359-364

8 Beigel Y, Bar J, Cohen M, Hod M. Pregnancy outcome in familial homozygous hypercholesterolemic females treated with longterm plasma exchange. Acta Obstet Gynecol Scand 1998;77: 603-608 
9 Fahed AC, Nemer GM. Familial hypercholesterolemia: the lipids or the genes? Nutr Metab (Lond) 2011;8:23

10 Hameed AB, Tummala PP, Goodwin TM, et al. Unstable angina during pregnancy in two patients with premature coronary atherosclerosis and aortic stenosis in association with familial hypercholesterolemia. Am J Obstet Gynecol 2000;182:1152-1155

11 Mabuchi H, Sakai Y, Watanabe A, Haba T, Koizumi J, Takeda R. Normalization of low-density lipoprotein levels and disappear- ance of xanthomas during pregnancy in a woman with heterozygous familial hypercholesterolemia. Metabolism 1985;34: 309-315

12 Shiomi M, Ito $T$, Watanabe $\mathrm{Y}$. Increase in hepatic lowdensity lipoprotein receptor activity during pregnancy in Watanabe heritable hyperlipidemic rabbits; an animal model for familial hypercholesterolemia. Biochim Biophys Acta 1987; 917:92-100 